\title{
Cryptosporidium Contamination and Attributed Risks in Yunlong Lake in Xuzhou, China
}

\author{
Yadong Kong, ${ }^{1}$ Ping Lu, ${ }^{1}$ Tao Yuan, ${ }^{2,3}$ Jinghui Niu, ${ }^{1}$ Zhaoji Li, ${ }^{1}$ and Baisong Yang ${ }^{1}$ \\ ${ }^{1}$ School of Environment Science and Spatial Informatics, China University of Mining and Technology, Xuzhou 221000, China \\ ${ }^{2}$ Department of Architecture Equipment and Civil Engineering, Jiangsu Vocational Institute of Architectural Technology, \\ Xuzhou 221116, China \\ ${ }^{3}$ JiangSu Collaborative Innovation Center for Building Energy Saving and Construct Technology, Xuzhou 221116, China
}

Correspondence should be addressed to Ping Lu; lupingcumt@126.com

Received 27 October 2016; Revised 6 January 2017; Accepted 23 February 2017; Published 12 March 2017

Academic Editor: Helieh S. Oz

Copyright (C) 2017 Yadong Kong et al. This is an open access article distributed under the Creative Commons Attribution License, which permits unrestricted use, distribution, and reproduction in any medium, provided the original work is properly cited.

\begin{abstract}
Swimming in surface water bodies (e.g., lakes, rivers) can expose the human body to substantial risk of infection by Cryptosporidium. These findings are from a one-year investigation on the occurrence and distribution of the protozoan parasite Cryptosporidium in Yunlong Lake, Xuzhou, China. Cryptosporidium oocysts were detected by immunofluorescence microscopy. From January to November of 2015, 180 samples (120 water samples and 60 sediment samples) were collected and analyzed. Among them, 42 (35\%) water samples and 28 (47\%) sediment samples tested positive for Cryptosporidium. The concentration of Cryptosporidium oocysts in the water samples was $0-8 / 10 \mathrm{~L}$ and $0-260 / \mathrm{g}$ in sediment samples. Results revealed that July was the highest risk period for both swimming and diving with an estimated probability of infection from swimming of greater than 18 per 10,000 swim sessions. It was concluded that swimming or diving in Yunlong Lake has a higher risk of Cryptosporidium infection than the acceptable risk level set by the United States Environmental Protection Agency. Thus, regular monitoring of water quality in recreation water bodies is strongly recommended.
\end{abstract}

\section{Introduction}

Diarrhea is the third leading cause of deaths in the developing countries. Each year, about 1.8 million people die from diarrheal diseases worldwide, and $90 \%$ of the victims are children under the age of five $[1,2]$.

Cryptosporidiosis is a type of the diarrheal illness caused by the infection of Cryptosporidium. Cryptosporidium is especially dangerous for infants, children, older people, pregnant women, and individuals with Acquired Immune Deficiency Syndrome. There has been an increased prevalence of cryptosporidiosis in densely populated areas in China, such as Beijing, Shanghai, Jiangsu, and Anhui Province $[3,4]$. Most infections of Cryptosporidium stem from recreational water bodies [5]. Considering the risk of different ways of Cryptosporidium infection (i.e., drinking unboiled tap water and swimming and diving in the water bodies), swimming poses the highest risk of infection [6]. However, this exposure pathway for Cryptosporidium infection has received little attention in China.

Recreational water bodies can be contaminated by animal excretions, runoff from Cryptosporidium-contaminated soil, and discharge from wastewater treatment facilities and sewage systems [7]. A single infected animal excretion could contain billions of oocysts [5]. These oocysts are very resistant to many environmental stresses and can survive for a long period of time. Due to their small size and low settling velocity, they are very slow to settle out of watercourses [8]. For the above-mentioned reasons, swimmers health is highly jeopardized when they swim in recreational water bodies.

The primary purpose of this paper is to show the distribution of Cryptosporidium in the Yunlong Lake and to discuss the potential health risks while swimming or diving in this lake. 


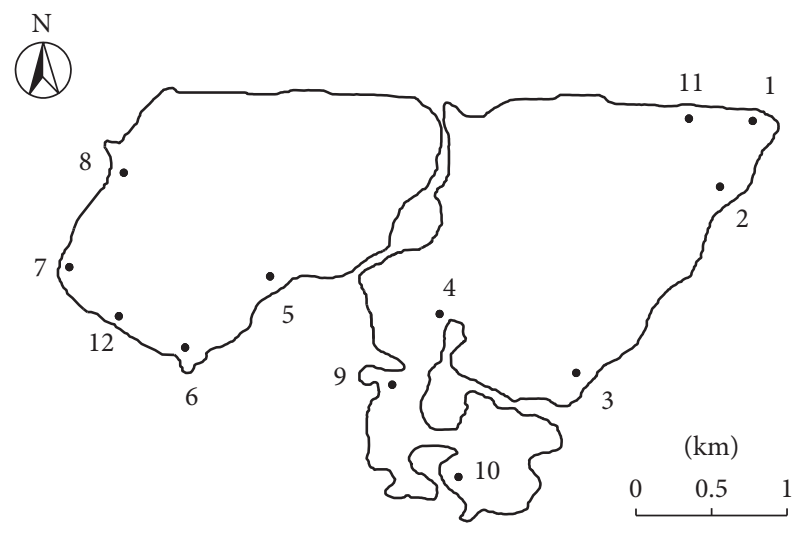

Figure 1: Sample collection sites.

\section{Methods}

Yunlong Lake is located in the southwest of Xuzhou City and has a surface area of $6.8 \mathrm{~km}^{2}$ and perimeter of $12 \mathrm{~km}$. It is a recreational aquatic venue used for swimming and boating. A total of 120 water samples and 60 sediments samples were collected from 12 sampling sites along the lake (as shown in Figure 1). The sampling sites included restaurants, docks, fishing areas, boating training bases, and areas around living quarters. In each sampling site, duplicate water samples were collected from 0.1-2 meters below the water surface. Approximately $10 \mathrm{~L}$ of water was collected in a $10 \mathrm{~L}$ sterile plastic tank. Sediment samples were taken by a piston cylindrical sampler (KHT0204, Yinhua, Shangyu). Water and sediment samples were collected five times in January, March, July, August, and November 2015. The months for sampling, July and August, are the highest flow months of the year as well as the peak summer vacation months in China. Therefore, the proportion of people swimming in this two-month period is very high in comparison to the rest of the year. January and November were chosen because they are the driest months reported in this region.

Water samples were filtered through membrane filters with a pore size of $2 \mu \mathrm{m}$ by a vacuum device and concentrated using two centrifugation steps at $4,000 \times \mathrm{g}$ at $4^{\circ} \mathrm{C}$ for 15 minutes, followed by two microcentrifugation steps at $15,000 \times \mathrm{g}$ at $4^{\circ} \mathrm{C}$ for 5 minutes. The entire resuspended pellet was transferred into the slide wells. Sediment samples (20 g) taken from each site were mixed with distilled water and concentrated using two centrifugation steps at $2,000 \times \mathrm{g}$ at $4^{\circ} \mathrm{C}$ for $20 \mathrm{~min}$, discarding the supernatant and mixing the pellet with distilled water. The mixed solution was taken and transferred into a microcentrifuge tube and centrifuged at $2000 \times \mathrm{g}$ at $4^{\circ} \mathrm{C}$ for $10 \mathrm{~min}$ [9]. Cryptosporidium oocysts were numerated using an epifluorescence microscope under 200x magnification (Environmental Protection Agency (EPA) Method 1622) [10].

Exposure assessments consist of identifying the pathways (i.e., exposure routes: swimming and diving in the lake) and numbers of Cryptosporidium oocysts reaching a person and potentially leading to infection [6]. It has been reported about $18-37 \mathrm{~mL}$ of water is swallowed by swimmers per swimming event [11]. Additionally, 10.5-21.6\% of people swim twenty times per year, and people swim an average of once a week during the summer [12]. Further, approximately $2.8-13 \mathrm{~mL}$ of water is swallowed for each dive and the estimated risk of diving was $2.1 \%$ for divers [13]. The studied area, Xuzhou, has a similar situation when compared with the previous research areas [6]. Therefore, the exposure frequency and population proportion were adopted for risk assessment in this study.

The exponential dose response model was used to estimate the infection risk of a single exposure [6], and the model is shown below:

$$
P_{i}=1-e^{-r N},
$$

where " $P$ " is the probability of infection and " $r$ " shows the probability that Cryptosporidium can reach and infect a person. According to United States Environmental Protection Agency (USEPA), $r_{\text {Cryptosporidium }}=0.09$ [14]. $N$ is the dose, calculated by

$$
N=\frac{C V}{\mathrm{rec}}
$$

where " $C$ " is the detected Cryptosporidium concentration in water samples, with unit of number of Cryptosporidium per liter $(\mathrm{n} / \mathrm{L})$, rec is the recovery rate (rec was 0.3$)$, and " $V$ " is individual consumption of water in liters $(\mathrm{L})[6,15,16]$.

An individual annual risk is defined as the risk associated with an individual's exposure to Cryptosporidium over a period of the year. The calculation of annual risk of infection, " $P_{i y}$, " is shown as below:

$$
P_{i y}=1-\left(1-P_{i}\right)^{n}
$$

where " $n$ " is the annual exposure number.

Beta probability density distribution was used to model the probability of annual illness that a healthy consumer is infected by Cryptosporidium [17]. The annual illness risk is shown as follows:

$$
P_{i l y}=P_{i y} \times P_{i l},
$$

where " $P_{i l y}$ " is probability of annual illness and " $P_{i l}$ " is probability of illness given infection.

Table 1 gives the model parameters for risk assessment of Cryptosporidium in Yunlong Lake.

\section{Results}

Figures 2 and 3 show the level of Cryptosporidium oocysts in water and sediment samples, respectively. Cryptosporidium oocysts were $0-8 / 10 \mathrm{~L}$ (with a mean value of 2.6/10 L) in water samples and $0-260 / g$ (with a mean value of 129 oocysts/g) in sediment samples. The detection results of the samples are shown in Table 2. A higher incidence of Cryptosporidium positive samples was found in the rainy season (i.e., JulyAugust) as compared to the results obtained in other periods. The seasonal pattern of Cryptosporidium in Yunlong Lake is similar to the Three Gorges Reservoir, China [6]. Cryptosporidium in water samples of sampling sites 9 and 12 was 
TABLE 1: Model parameters for risk assessment of Cryptosporidium.

\begin{tabular}{lc}
\hline Variable description (unit) & Mean \\
\hline January average oocysts concentration, sites 1-12 (per 100 L) & 25 \\
March average oocysts concentration, sites 1-12 (per 100 L) & 15 \\
July average oocysts concentration, sites 1-12 (per 100 L) & 33 \\
August average oocysts concentration, sites 1-12 (per 100 L) & 30 \\
November average oocysts concentration, sites 1-12 (per 100 L) & 26 \\
Water ingestion volume by swimming in the lake (mL/time) & 37 \\
Water ingestion volume by diving in the lake (mL/time) & 13 \\
Percentage of exposure swimmers (\%) & 16.05 \\
Percentage of exposure divers (\%) & 2.1 \\
Infectivity of annual exposures for swimming (times) & 20 \\
Infectivity of annual exposures for diving (times) & 19.82 \\
Probability of illness given infection & 0.5 \\
\hline
\end{tabular}

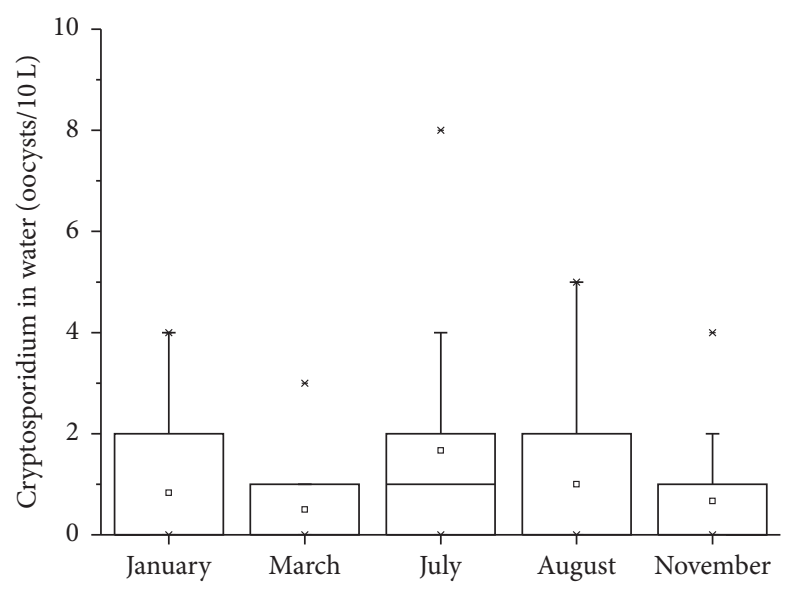

FIGURE 2: Cryptosporidium oocysts in water samples.

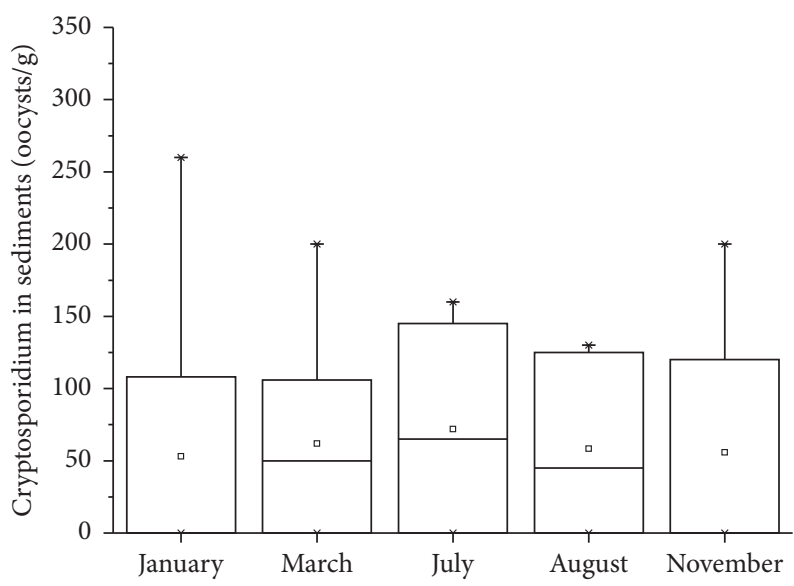

FIGURE 3: Cryptosporidium oocysts in sediment samples.

detected positive for the whole year. It was also observed that water at sampling sites 9 and 12 was very cloudy.

Table 4 shows the risk of infection and illness by swimming and diving exposure in the lake according to the measured oocysts number per liter of the lake water.
TABle 2: Sample detection results for the 12 sites in Yunlong Lake, Xuzhou, 2015.

\begin{tabular}{lcc}
\hline & $\begin{array}{c}\text { Number of the } \\
\text { positive samples } \\
\text { detected }\end{array}$ & $\begin{array}{c}\text { Positivity rate in } \\
\text { percent }\end{array}$ \\
\hline January & 4 & $33.3 \%$ \\
Water & 5 & $41.7 \%$ \\
$\quad$ Sediment & & \\
March & 4 & $33.3 \%$ \\
Water & 6 & $50.0 \%$ \\
Sediment & & \\
July & 6 & $50.0 \%$ \\
Water & 6 & $50.0 \%$ \\
Sediment & & \\
August & 4 & $33.3 \%$ \\
$\quad$ Water & 6 & $50.0 \%$ \\
Sediment & & \\
November & 3 & $41.7 \%$ \\
$\quad$ Water & 5 & \\
Sediment & & \\
\hline
\end{tabular}

Swimming in July has the highest infection risk of $1.85 \times 10^{-3}$ per time, while swimming in March has the lowest infection risk of $5.55 \times 10^{-4}$ per time. Swimming in July has the highest yearly infection $\left(3.64 \times 10^{-2}\right)$ and illness risks $\left(1.82 \times 10^{-2}\right)$.

Table 5 shows the risk of infection and illness caused by diving exposure in the lake according to measured oocysts number per liter of the lake water. Diving in July has the highest infection risk of $6.51 \times 10^{-4}$ per time, while diving in March has the lowest infection risk of $1.95 \times 10^{-4}$ per time. Diving in July has the highest yearly infection $\left(1.29 \times 10^{-2}\right)$ and illness risks $\left(6.45 \times 10^{-3}\right)$.

\section{Discussions}

Cryptosporidium have been detected in source water bodies worldwide [15, 18-20]. However, cryptosporidiosis outbreak 
TABLE 3: Occurrence of Cryptosporidium in water collected from various sites in China.

\begin{tabular}{|c|c|c|c|c|}
\hline Location of sampling & Mean (oocysts/10 L) & Positive rate & Year of sampling & Reference \\
\hline The Three Gorges Reservoir & 1.92 & $100 \%$ & 2011 & [6] \\
\hline River network system, Tongxiang & 5.1 & $78.7 \%$ & 2009 & [23] \\
\hline Water samples in Qinghai & N/A & $25.4 \%$ & 2011-2012 & [24] \\
\hline Waterworks in 33 major cities & 0.7 & N/A & 2009-2011 & [25] \\
\hline Huangpu River & N/A & $37.6 \%$ & 2013-2014 & [26] \\
\hline Wastewater treatment plants in Harbin & N/A & $31.3 \%$ & $2009-2010$ & {$[27]$} \\
\hline Source water, Shanghai & 5.2 & $32 \%$ & 2009-2010 & {$[28]$} \\
\hline Recreational water, Xuzhou & 0.97 & $35 \%$ & 2015 & This manuscript \\
\hline
\end{tabular}

TABLE 4: Simulated risks by exposure events in Yunlong Lake (swimming).

\begin{tabular}{lccc}
\hline Exposure routes & Probability of infection per time & Probability of infection per year & Probability of illness per year \\
\hline Swimming in January & $9.21 \times 10^{-4}$ & $1.83 \times 10^{-2}$ & $9.15 \times 10^{-3}$ \\
Swimming in March & $5.55 \times 10^{-4}$ & $1.10 \times 10^{-2}$ & $5.51 \times 10^{-3}$ \\
Swimming in July & $1.85 \times 10^{-3}$ & $3.64 \times 10^{-2}$ & $1.82 \times 10^{-2}$ \\
Swimming in August & $1.11 \times 10^{-3}$ & $2.20 \times 10^{-2}$ & $1.10 \times 10^{-2}$ \\
Swimming in November & $7.43 \times 10^{-4}$ & $1.48 \times 10^{-2}$ & $7.40 \times 10^{-3}$ \\
\hline
\end{tabular}

TABLE 5: Simulated risks by exposure events in Yunlong Lake (diving).

\begin{tabular}{lccc}
\hline Exposure routes & Probability of infection per time & Probability of infection per year & Probability of illness per year \\
\hline Diving in January & $3.24 \times 10^{-4}$ & $6.46 \times 10^{-3}$ & $3.23 \times 10^{-3}$ \\
Diving in March & $1.95 \times 10^{-4}$ & $3.89 \times 10^{-3}$ & $1.95 \times 10^{-3}$ \\
Diving in July & $6.51 \times 10^{-4}$ & $1.29 \times 10^{-2}$ & $6.45 \times 10^{-3}$ \\
Diving in August & $3.90 \times 10^{-4}$ & $7.77 \times 10^{-3}$ & $3.89 \times 10^{-3}$ \\
Diving in November & $2.61 \times 10^{-4}$ & $5.21 \times 10^{-3}$ & $2.61 \times 10^{-3}$ \\
\hline
\end{tabular}

in recreational water is more frequent than in source water [5]. This study provides information on Yunlong Lake contamination by Cryptosporidium. The incidence of Cryptosporidium was not found to be higher than other water bodies reported in China (Table 3). Cryptosporidium was more frequently detected in sediments than that of surface water in Yunlong Lake (with positive rate of $47 \%$ and $35 \%$ for sediments and surface water, resp.) (Table 2). In the present study, Cryptosporidium concentration in sediment samples was not strongly correlated with those of water samples with a correlation coefficient of only 0.23 . Oocysts cannot be homogeneously distributed throughout the water [21], which could help to understand the weak correlation between Cryptosporidium concentration in water and in sediments. An obvious seasonal contamination pattern was observed, with higher Cryptosporidium frequency in summer compared to the other seasons, which was similar to Xiao's report [6].

Modeling results indicated a potential health risk for people swimming or diving in Yunlong Lake. Compared to diving, swimming has the higher infection risk (Table 4). Similarly, An and coworkers reported that swimming is the primary risk of Cryptosporidium infection in rivers [22].
In regard to an acceptable risk level, an annual individual infection risk of $10^{-4}$ was suggested by the USEPA. The average infection risks of Cryptosporidium for swimmers and divers in Yunlong Lake were all greater than the USEPA's acceptable risk level (Tables 4 and 5).

A compilation of Cryptosporidium concentrations in water samples from other study areas is listed in Table 3. Average concentration of Cryptosporidium oocysts in the present study $(2.6 / 10 \mathrm{~L}$ water) is comparable to the others. Watersheds from most of China have similar or higher Cryptosporidium positive rates in comparison with Yunlong Lake.

\section{Conclusions}

On the basis of the above results and discussions, it was concluded that swimming in Yunlong Lake has a higher risk of Cryptosporidium infection than the acceptable risk level set by the USEPA. Multiple-site monitoring of recreational water quality and timely reporting of information regarding infection risk are strongly recommended based on the data showing that this lake is indeed contaminated by Cryptosporidium. 


\section{Abbreviations}

USEPA: United States Environmental Protection Agency.

\section{Conflicts of Interest}

The authors declare that there are no conflicts of interest regarding the publication of this paper.

\section{Acknowledgments}

The authors wish to thank the "the Fundamental Research Funds for the Central Universities" (2017QNA35), National Natural Science Foundation of China (41403090), and the Foundation of JiangSu Collaborative Innovation Center for Building Energy Saving and Construct Technology (SJXTY1507).

\section{References}

[1] WHO, Water, Sanitation and Hygiene Links to Health, World Health Organization, Geneva, Switzerland, 2004.

[2] WHO, The Globle Burden of Disease: 2004 Update, World Health Organization, Geneva, Switzerland, 2008.

[3] Q.-Q. Wang, J.-D. Guo, Z.-G. Cao, G.-Z. Wan, D.-H. Liu, and T.P. Wang, "Investigation on human Cryptosporidium infection in local area of Anhui Province," Chinese Journal of Schistosomiasis Control, vol. 27, no. 3, pp. 263-272, 2015.

[4] Y. Feng, L. Wang, L. Duan et al., "Extended outbreak of cryptosporidiosis in a pediatric hospital, China," Emerging Infectious Diseases, vol. 18, no. 2, pp. 312-314, 2012.

[5] P. Lu, T. Yuan, Q. Feng, A. Xu, and J. Li, "Review of swimmingassociated Cryptosporidiosis and cryptosporidium oocysts removals from swimming pools," Water Quality Research Journal of Canada, vol. 48, no. 1, pp. 30-39, 2013.

[6] G. Xiao, Z. Wang, J. Chen et al., "Occurrence and infection risk of waterborne pathogens in Wanzhou watershed of the Three Gorges Reservoir, China," Journal of Environmental Sciences, vol. 25, no. 9, pp. 1913-1924, 2013.

[7] K. Balthazard-Accou, U. Fifi, P. Agnamey, J. A. Casimir, P. Brasseur, and E. Emmanuel, "Influence of ionic strength and soil characteristics on the behavior of Cryptosporidium oocysts in saturated porous media," Chemosphere, vol. 103, pp. 114-120, 2014.

[8] T. K. Graczyk, B. M. Evans, C. J. Shiff, H. J. Karreman, and J. A. Patz, "Environmental and geographical factors contributing to watershed contamination with Cryptosporidium parvum oocysts," Environmental Research, vol. 82, no. 3, pp. 263-271, 2000.

[9] S. Hong, K. Kim, S. Yoon, W.-Y. Park, S. Sim, and J.-R. Yu, "Detection of Cryptosporidium parvum in environmental soil and vegetables," Journal of Korean Medical Science, vol. 29, no. 10, pp. 1367-1371, 2014.

[10] EPA, Method 1622: Cryptosporidium in Water by Filtration/ $I M S / F A$, United States of Environmental Protection Agency, 2005.

[11] F. M. Schets, J. F. Schijven, and A. M. de Roda Husman, "Exposure assessment for swimmers in bathing waters and swimming pools," Water Research, vol. 45, no. 7, pp. 2392-2400, 2011.
[12] W. An, D. Zhang, S. Xiao, J. Yu, and M. Yang, "Quantitative health risk assessment of cryptosporidium in rivers of Southern China based on continuous monitoring," Environmental Science and Technology, vol. 45, no. 11, pp. 4951-4958, 2011.

[13] J. Schijven and A. M. de Roda Husman, "A survey of diving behavior and accidental water ingestion among dutch occupational and sport divers to assess the risk of infection with waterborne pathogenic microorganisms," Environmental Health Perspectives, vol. 114, no. 5, pp. 712-717, 2006.

[14] EPA, Economic Analysis for the Long Term 2 Enhanced Surface Water Treatment Rule, U.S. Environmental Protection Agency, Office of Water, Washington, DC, USA, 2005.

[15] F. M. Schets, J. H. Van Wijnen, J. F. Schijven, H. Schoon, and A. M. De Roda Husman, "Monitoring of waterborne pathogens in surface waters in Amsterdam, the Netherlands, and the potential health risk associated with exposure to Cryptosporidium and Giardia in these waters," Applied and Environmental Microbiology, vol. 74, no. 7, pp. 2069-2078, 2008.

[16] A. Ferrer, H. Nguyen-Viet, and J. Zinsstag, "Quantification of diarrhea risk related to wastewater contact in Thailand," EcoHealth, vol. 9, no. 1, pp. 49-59, 2012.

[17] E. Cummins, R. Kennedy, and M. Cormican, "Quantitative risk assessment of Cryptosporidium in tap water in Ireland," Science of the Total Environment, vol. 408, no. 4, pp. 740-753, 2010.

[18] M. Y. Lee, E. J. Cho, J. H. Lee, S. H. Han, and Y. S. Park, “A survey of Cryptosporidium oocysts in water supplies during a 10-year period (2000-2009) in Seoul," Korean Journal of Parasitology, vol. 48, no. 3, pp. 219-224, 2010.

[19] R. Briancesco and L. Bonadonna, "An Italian study on Cryptosporidium and Giardia in wastewater, fresh water and treated water," Environmental Monitoring and Assessment, vol. 104, no. 1-3, pp. 445-457, 2005.

[20] C. Mons, A. Dumètre, S. Gosselin, C. Galliot, and L. Moulin, "Monitoring of Cryptosporidium and Giardia river contamination in Paris area," Water Research, vol. 43, no. 1, pp. 211-217, 2009.

[21] C. L. DiGiorgio, D. A. Gonzalez, and C. C. Huitt, "Cryptosporidium and Giardia recoveries in natural waters by using environmental protection agency method 1623," Applied and Environmental Microbiology, vol. 68, no. 12, pp. 5952-5955, 2002.

[22] W. An, D. Zhang, S. Xiao, J. Yu, and M. Yang, "Quantitative health risk assessment of Cryptosporidium in rivers of Southern China based on continuous monitoring," Environmental Science and Technology, vol. 45, no. 11, pp. 4951-4958, 2011.

[23] S. Xiao, W. An, Z. Chen, D. Zhang, J. Yu, and M. Yang, "Occurrences and genotypes of Cryptosporidium oocysts in river network of southern-eastern China," Parasitology Research, vol. 110, no. 5, pp. 1701-1709, 2012.

[24] L. Ma, I. Sotiriadou, Q. Cai et al., "Detection of Cryptosporidium and Giardia in agricultural and water environments in the Qinghai area of China by IFT and PCR," Parasitology research, vol. 113, no. 9, pp. 3177-3184, 2014.

[25] S. Xiao, W. An, Z. Chen, D. Zhang, J. Yu, and M. Yang, "The burden of drinking water-associated cryptosporidiosis in China: the large contribution of the immunodeficient population identified by quantitative microbial risk assessment," Water Research, vol. 46, no. 13, pp. 4272-4280, 2012.

[26] Y. Hu, Y. Feng, C. Huang, and L. Xiao, "Occurrence, source, and human infection potential of Cryptosporidium and Enterocytozoon bieneusi in drinking source water in Shanghai, China, 
during a pig carcass disposal incident," Environmental Science and Technology, vol. 48, no. 24, pp. 14219-14227, 2014.

[27] A. Liu, H. Ji, E. Wang et al., "Molecular identification and distribution of Cryptosporidium and Giardia duodenalis in raw urban wastewater in Harbin, China," Parasitology Research, vol. 109, no. 3, pp. 913-918, 2011.

[28] Y. Feng, X. Zhao, J. Chen et al., "Occurrence, source, and human infection potential of Cryptosporidium and giardia spp. in source and tap water in Shanghai, China," Applied and Environmental Microbiology, vol. 77, no. 11, pp. 3609-3616, 2011. 


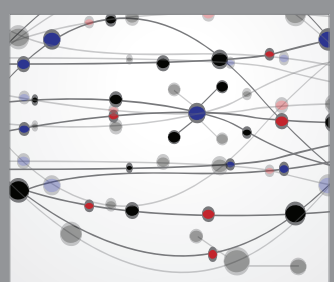

The Scientific World Journal
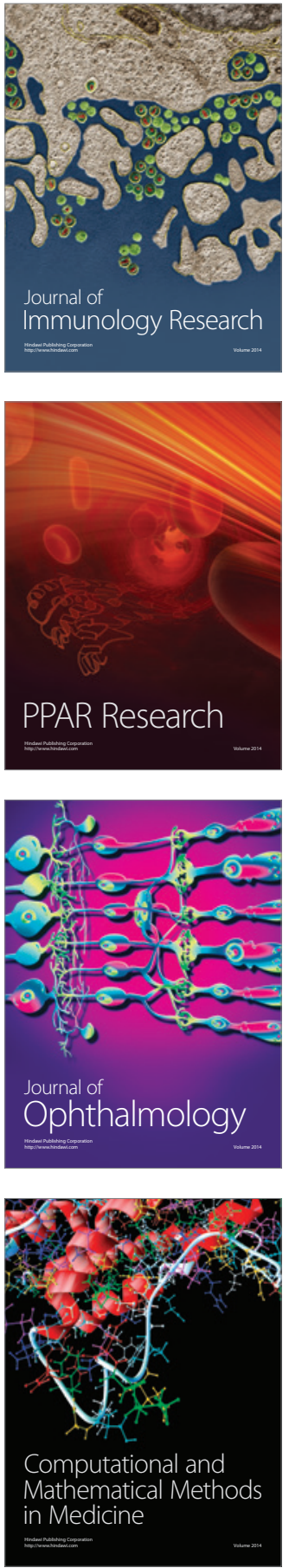

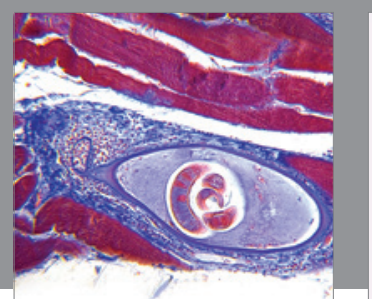

Gastroenterology Research and Practice
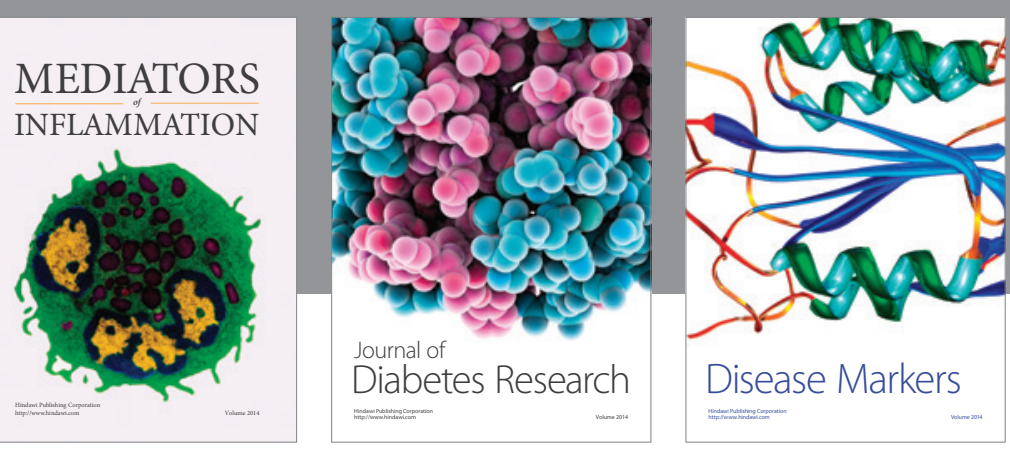

Disease Markers

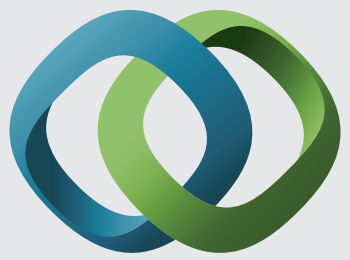

\section{Hindawi}

Submit your manuscripts at

https://www.hindawi.com
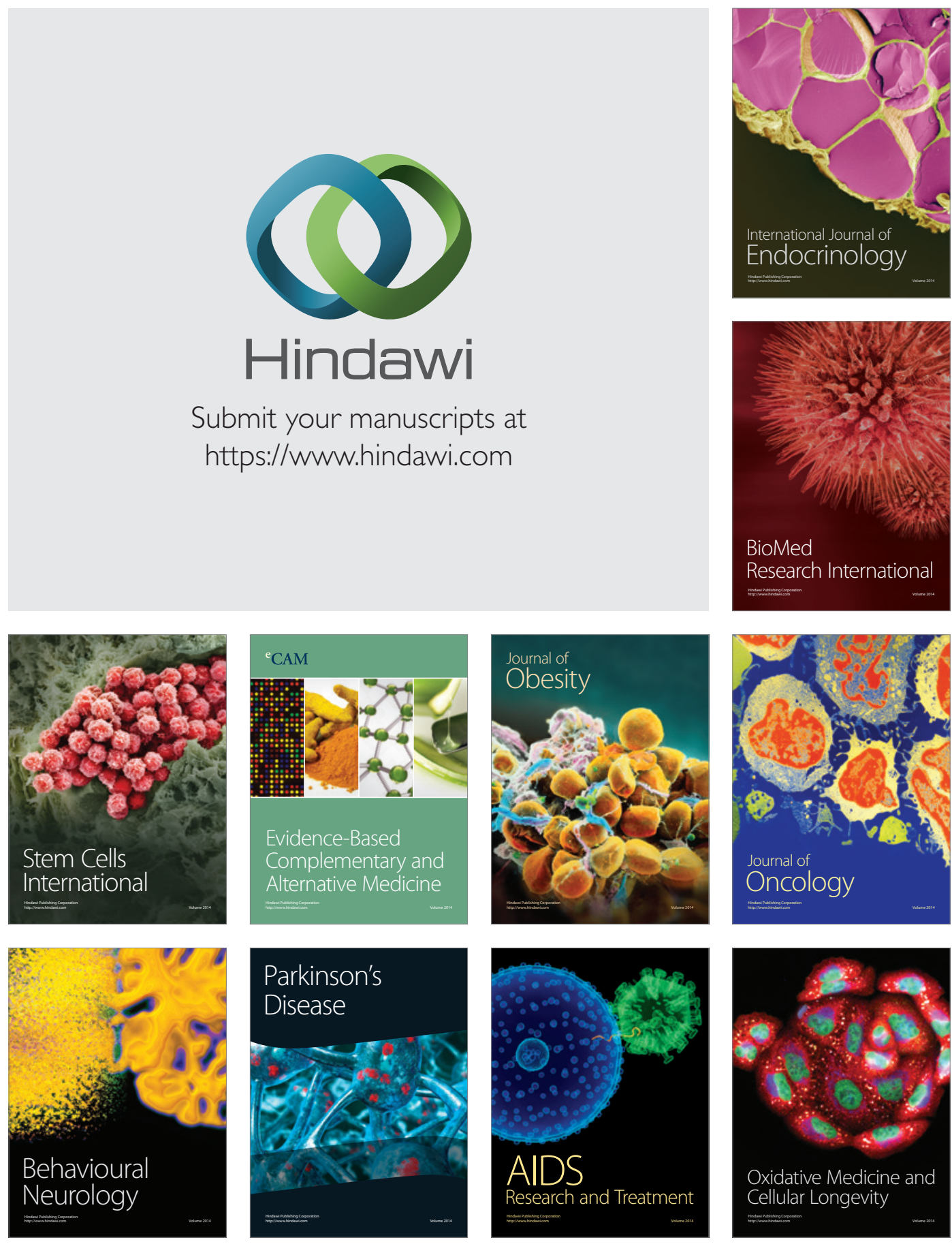